\title{
The Missing Stream: Fostering Music Products Education Through Applied Technology
}

\author{
Paul Linden \\ Butler University \\ This paper was presented at the 2018 International Summit of the \\ Music \& Entertainment Industry Educators Association \\ March 22-24, 2018
}

https://doi.org/10.25101/18.32

\begin{abstract}
This paper argues for an expanded view of music industry education through greater recognition of the largely overlooked music products sector. Music products and applied audio technology represent growth areas for music industry programs managing their own brand identities. An initial perspective reveals major trends facing top companies in this $\$ 7$ billion industry. Analysis of how this area is being addressed in the academy refers to three existing institutional models. This in turn shows that even though applied audio tech is a useful approach into a music products emphasis, bringing fabrication in-house is a challenging concept for music, business, and communications departments. Recommended strategic alliances include disciplinary overlap with coursework based in physics, theater, and live event management and production programs. Justifications for such an emphasis include market forces like stable growth, employment, and economic value as well as the ability to respond to student demand for active and experiential learning. The study concludes with a sample course project to show an example of what applied audio coursework looks like.
\end{abstract}

Keywords: music products, music business education, curriculum development, applied audio technology, interdisciplinary studies, physics
A relative anomaly on the landscape of higher education during the last decades of the twentieth century, colleges, universities and even high schools offering music industry coursework have awoken to its recruiting power in the twenty-first century. Departments and schools offering such programs are no strangers to the collision of opposing forces operating at the intersection of industry, commerce, and education. On the one hand, we see the speed of technology, business-minded mantras echoing the old "time is money" equation and the need to follow quickly shifting cultural trends. On the other hand, we see higher education operating at a far slower pace laboring to push innovation through layers of committees in the effort to ultimately locate it somewhere under the rubrics of research, teaching, or service. After all, if successful businesses tend to measure their lifespans by the decade, colleges and universities do so by the century. For disciplines like music, business, and communications circulating around the popular music industry, this broad perspective is useful for recognizing some of the opposing forces involved in growing music industry programs. Despite its relative slowness, the academy prides itself in its ability to reduce complex systems like the music industry to an essential set of principles that remain valid even as practices and technologies shift. Music industry scholarship thus faces the threat of operating at a much slower pace than its subject. The tension that results is exemplified by a cornerstone of music industry education - the " 3 streams" model set forth by Geoffrey Hull in 2001. In its reduction of the recording industry to the basic components of songwriting and performance as they feed into label operations, the text fundamentally ignores the question of how songwriters, engineers, and performers are supplied with the tools of their respective crafts: the musical instruments, recording and live performance equipment that captures and conveys creative inspiration for awaiting consumers.

Rather than pursuing an interrogation of how this apparent oversight happened, let us consider the possibility of including music products alongside of those other income 
streams mentioned above. Important as a topic of reflection, that in itself however is not our aim. Instead, the ultimate aim of the work at hand is to recognize the study of music products as an opportunity for this young discipline to make a stronger claim to its academic territory, increase its relevance, and better prepare students for success. To this end, let us consider this subject area in terms of its recent evolution and its relative lack of visibility in music industry literature before bringing focus onto how a collection of sample academic programs represent a variety of pathways for adoption. From that perspective, we will focus on applied music technology as a preferred way to address music products and as a means of creating experiential learning opportunities in a hands-on classroom. And this allows us to address fundamental questions like, what overarching student learning objectives guide the inclusion of music products as an area of study? And, what could an introductory as opposed to intermediate or even upper-level music products course of study look like? Finally, this paper includes a sample upper-level course project to demonstrate how students learn in this subject area as well outlining practical considerations like specialized equipment, software, and additional cost.

\section{The Shifting Landscape of Music Products}

From a purely financial perspective, the case for including the products sector within a revamped "four-streams" model is one that justifies itself with ease. For many students of the industry, the significance of the 2017 U.S. numbers has been the concert revenues ( $\$ 8$ b) as compared to label income (\$7.8b). Echoing the same shift in the U.K. numbers from 2014, the importance of this shift has been read as a confirmation of the live performance sector as the industry driver. While this is no doubt a bellwether event even from the long-term view, it also signifies the turbulent conditions working to reorganize the creative industries over the last fifteen to twenty years. Given the precipitous fall of the record business over that time, the comparative stability of the U.S. music products industry over the last decade is remarkable by contrast. Over the last decade, the products sector has quietly maintained a steady $1.5 \%$ increase, growing from $\$ 7 \mathrm{~b}$ to $\$ 7.1 \mathrm{~b}$. By economic value alone then, the products market assumes the third position in a would-be four-stream model, keeping music licensing at the bottom rung with its $\$ 5.5$ b in 2017 (see Figure 1).

Simply put, the music products sector consists primarily of musical instruments, audio equipment (sound reinforcement, studio and home recording hardware and software) as well as accessories, lessons, and repair services. Within the products sector itself, we find a significant shift in the landscape impacting the way business is done and reflecting many of the same forces at work in the larger retail con-

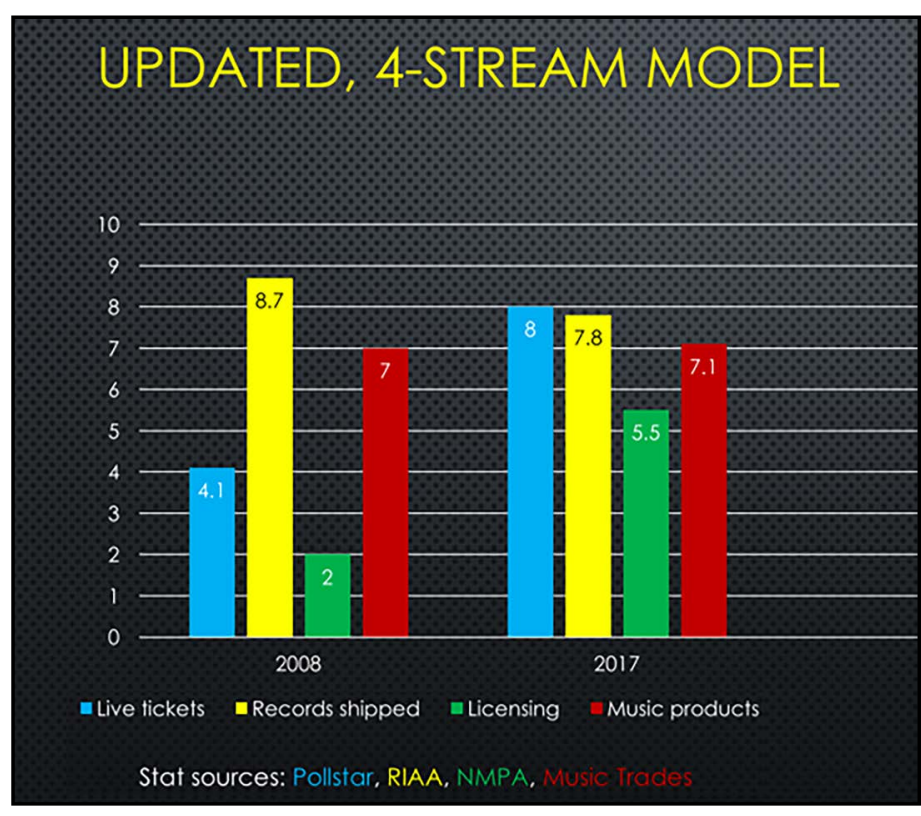

Figure 1. Updated four-stream model.

sumer marketplace. For the last half century, Guitar Center Holdings $(\mathrm{GCH})$ has built itself into the leading position among industry retailers. However, it appears that the company continues to struggle with accommodating to the progressively online marketplace. While recent figures are more difficult to obtain, research has yielded a digital copy of GCH's 2012 statement of financial performance to the Securities and Exchange Commission (form 10-K) showing consolidated long-term debt of approximately $\$ 1.5$ billion. More recent press reveals GCH's complex shell game of transferring debt as largely ineffective leading some analysts to estimate the current figure as being closer to $\$ 1.9$ billion. Regardless of speculation, in 2012, GCH's debt equaled $21.43 \%$ of the total value of the music products sector.

Indiana-based Sweetwater Sound Incorporated provides a contrasting perspective on the upper echelons of the music products industry. It would be an oversimplification to say that Sweetwater has completely eschewed the brick and mortar albatross to which Guitar Center remains tied. Instead, Sweetwater presents a consolidated model based out of a modern 150,000 square foot campus on 99 acres in rural, northeast Indiana (see Figure 2).

The campus houses a wide array of operations from a traditional brick and mortar retail space to warehouse/shipping facilities, online and phone-based tech support, exposition halls, a suite of recording studios, in-house customization services, an array of employee services including a gym and barber/salon, as well as a host of community-facing spaces like its amphitheater, instrument repair, dining hall, and interactive arcades. The apparent incongruity of a Silicon Valley style of campus in the Midwestern countryside is off- 


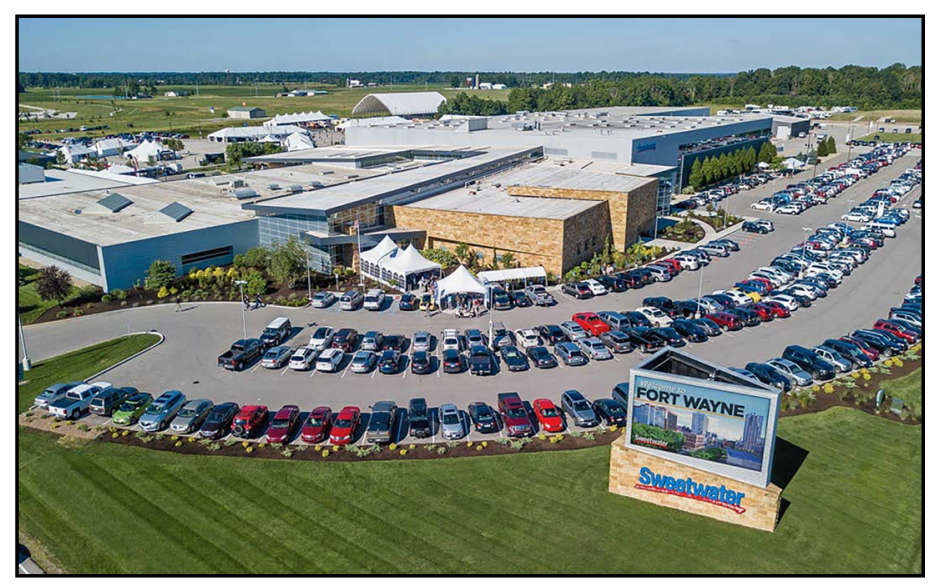

Figure 2. Sweetwater Sound, Inc., Fort Wayne, Indiana.

set by the amount of business Sweetwater conducts online shipping approximately 800 guitars per day. The sales floor hosts some 300 reps each doing an equivalent amount of business as a single brick and mortar Guitar Center location. In addition, the sales floor rents out office space to reps from Fender, Avid, Shure, and a host of other manufacturers to liaise large-scale wholesale buying as necessary.

\section{Academic Integration}

A good indicator of the current status of music products in music industry education is the fact that the topic receives all of one chapter's worth of visibility in Baskerville's $M u$ sic Business Handbook - a textbook typically found in a first-year intro class. While the topic is not completely invisible, it threatens to be marginalized and all but forgotten by the time students graduate. This is clearly not suitable for the third most valuable sector of the music business. So, what implications does music products hold for higher education? While a complete answer to this question is too vast given the scope of this one article, let us take a closer look at how an emphasis on music products might be best situated within an existing music industry program. To speak to this issue, we will take a twofold approach. From the perspective of the institution, it is important to recognize points of disciplinary overlap that may be able to facilitate and support the implementation and development of younger academic initiatives such as the creation of an area of emphasis in music products. As a follow-up to this discussion, we will consult a sample set of existing university courses and programs that represent reference points for our study. This perspective will provide an idea of how such an initiative might be integrated as an exploratory startup, a concentration, or even a minor or major area of study. Together, these two points of view can serve as a guide to identify necessary resources and support structures along with sample blueprints of how consulted programs have been seeded and developed towards fruition.
An initial question to inform our inquiry of how to address the addition of music products courses to a given music industry program would be, what relationships can we find between the study of products and the traditional disciplinary network we find supporting music industry programs? Looking at how music industry programs are currently situated in universities by college or school, it is an established point of fact that music, business, and communications are the traditional triad disciplinary partners. If the core competencies or outcomes most often associated with music industry programs include management (music business operations like artist, event, or label management), production (live sound reinforcement, studio engineering, editing) and performance/composition, then products certainly borrows elements from all of these. In fact, the effort of product development is to translate a performer's preferences into technical terms in order to create an effective item (instrument, component, or production) that hopefully responds to an entrepreneurial niche or opportunity. However, the actual fabrication component whether it be through software coding or physical design and assembly places a significant part of this area into academic territory usually covered by computer science (coding) and physics (electrical design and assembly).

The above situation is noteworthy for several reasons as we proceed. First of all, it represents significant but not prohibitive departure from the "way things tend to be done" in a given music industry program. As such, a music products initiative represents a true growth opportunity as opposed to a reorganization schema. Secondly, and as a result of this growth opportunity, it represents specialized knowledge, equipment, and safety considerations that may be daunting from music, performance, or business perspectives but less alien from that of a physics or hard science program. Access to specialized equipment types and the existing codification of best practices for their operation would then be a significant type of interdisciplinary support improving startup and general administrative efficiency. Third, and apart from these technical skills, some types of student learning objectives commonly associated with the more traditional music industry programs work well within the music products context. These include aesthetic awareness, brand strategy development, and recognition of marketplace dynamics. Lastly, just as the breadth of the products sector requires decisions to be made in terms of what kinds of products or services are to be featured, academic programs are likely to be forced into similar choices. These decisions should consider the market demands, the expertise of associated faculty as well as institutional resources (funds, equipment, space, etc.) that may make certain types of products or services more or less favorable or even viable. 


\section{An Applied Music Technology Approach}

The breadth of possibilities for the types of goods and services that could be featured by a music products academic initiative is very wide, potentially ranging from luthiery to music therapy, digital sampling and synthesis to piano tuning, instrument repair and so on. Deciding what type(s) of products or services to teach is of obvious importance (see the discussion above, as well as Baskerville's chapter showing which types of products are the most crucial to the sector's success). The programs consulted for the purposes of this study, it should be noted, all align under the general rubric of applied technology meaning that these are not courses or programs dealing in the service side of music products (i.e., lessons, repair, music therapy). Instead, the consulted programs offer instruction in physical and digital products like instrument amplifiers, effects pedals, audio programs (software, apps) as well as virtual and physical instruments. The rationale for this choice is informed primarily by the limited range of program types with emphasis on products. Furthermore, these examples range from a single course (as in the case of the University of Illinois at Urbana-Champaign), to a combination of multiple courses oriented towards the music products industry and serving as a concentration or certificate within a broader major (as in the case of Appalachian State University), to a dedicated major with its own core of classes (as in the case of Massey University of New Zealand's College of Creative Arts; see Appendix 1 for media relative to these programs).

At the most basic level, an applied technology-type of music products course may organically take root in a single experimental course, science lab section, or theater workshop. These environments can be catalysts when, for example, the combination of specialized equipment with a passing orientation toward the creative/cultural industries results in repairing or modification of existing audio equipment or the creation of custom pieces. This is to say that some institutions unwittingly foster conditions for these factors to coalesce without any overt tie to music industry education. In the example of the University of Illinois at Urbana-Champaign, the department of Physics developed a physics of music course (Physics 406) driven largely by the professor's hobbies in music and electronics in combination with the availability of the university's audio lab space and equipment. Students choose the course as an upper-level elective and, after reviewing the relevant acoustic and electrical theory, they propose a project for the course and spend their time building music equipment. Students are able to choose their projects based on personal interest and ability. The fact that these tend heavily towards guitar (effects pedals, amplifiers), ultimately reflects the distribution of the music products marketplace as shown by Baskerville. Because the course directly responds to the vogue of hands-on, experiential learning, its designer, professor Steven Errede stayed on past his intended retirement to teach only this course due to student demand.

Beyond this example, we find a secondary or intermediate degree of integration in the case of Appalachian State University. The Hayes School of Music offers a Bachelor of Science in Music Industry Studies with a possible concentration in Music Manufacturing and Merchandising. In this example, music industry students pass required courses in musicianship, performance, and music industry before moving onto a three-course sequence focused on entrepreneurship, selling, and internet marketing. This sequence shares two prerequisites, a 200-level class in music merchandising and entrepreneurship as well as a 300-level class in marketing principals. Here, the music products sector is addressed through a classroom-based, conceptual model integrated with a more experiential one in which the applied component is split between the practicum/field experience class (MUS 2901) and the upper-level music technology class (MUS 4420). Given the speed of the industry and the crucial importance of field experience for music industry students, the Appalachian State example allows the dynamics of the current marketplace to provide students with direct experience while simultaneously using the class to emphasize marketing and sales principals. While there is little basis or need for direct comparison of the two examples provided so far, it is striking that between them there is a rather comprehensive picture of a fully integrated program in which the institution is less dependent on the private sector for the means of production (i.e., fabrication).

Although research did not reveal a self-contained music products major, this should come as no surprise given that it is very uncommon for any of the traditional streams to find such unique emphasis in a four-year program. Nonetheless, Massey University of New Zealand's College of Creative Arts represents the most complete example of a comprehensive and integrated applied technology style of a music products course of study. The program is significantly different than the U.S. programs in that it is more intensive (completing in three years rather than four) and it places students' creative work at the start of the program rather than at the end. The course of study is a bachelor of commercial music that has three end-of-year major projects each with a subsequent orientation including "performance" in year one, "technology" in year two, and "music industry" in year three. To claim that the program is specifically dedicated towards music products would not be accurate. Rather, students entering with the desire to pursue music products exclusively would be able to use their time to choose a course of study that would combine the two previous examples we have consulted in this study. This is to say that by the end of the second year, students have the opportunity to take 
two software development classes and two hardware/electronics classes. Rather than proceeding from conceptual to experiential, Massey students begin with applied, creative projects and use their capstone year to conceptually plug that creativity into the industry map (survey course) as a culminating gesture.

\section{Sample Project-Based Activity}

A good way to show how a proposed area of study functions is through an example of the type of work it proposes for student engagement. The following example may be applied as a discrete (short-term) assignment or located in a larger, cumulative class project (upper level). The core idea of the project is a response to an entrepreneurial niche in the music products market place. Until the very recent uptick in custom amplifier building, the market was wide open for amplifiers designed for acoustic instruments like mandolin or fiddle that require reinforcement for larger stages. This remains an entrepreneurial opportunity to which few DIY enthusiasts are able to respond. This inability is supported, in part, by the separation of applied tech from the marketing, management, and sales skill-set common to music industry education. The project/assignment is thus aimed at modifying guitar amplifiers to work for other instruments. Harmonica has been used in the examples that follow. The competencies required for completing this project include those conveyed in lower-level physics or introductory audio courses (the nature of sound, frequency, basic electronics) as well as at least one additional audio electronics course to introduce reading schematics/circuit diagrams, safety protocol for working with electronics and the basics of audio measurement and circuit design.

Due to their relative simplicity and accessibility, older vacuum tube designs (as opposed to transistor-based designs) have been chosen as the platform for this sample project. As a small-scale activity, students would be primed with audio discretion (listening) exercises to develop an awareness of their preference regarding various amplifier manufacturers (Fender, Marshall, Valco, etc.) from different production periods (1940s through 1960s) with particular focus on how the tone control section shapes what they are hearing. Audio frequency analysis software (like SpectraFoo for example) is a useful tool for taking a snapshot of where acoustic energy is concentrated for a given instrument like the harmonica (see Appendix 2 for media relative to this research project). This is the equivalent of letting digital technology take a song's digital fingerprint, except here we are applying it to an instrument instead of a song. Using additional freeware like Seymour Duncan's Tone Stack Calculator, this information allows designers to cut and boost frequencies specific to that instrument and either design their own tone control circuit (short term assignment) or ultimately to build an amplifier (course project) that is designed specifically for that instrument. Despite additional course fees to cover students' building kits (\$200), students from the programs profiled above have discovered that building customized audio components fits well within the purview of a semester (see Appendix 3 for a list of specialized equipment and additional resources).

Like any business, institutions of higher education periodically change the way they market themselves. Current catch phrases like "interdisciplinary", "experiential", "hands-on", "transformative" are not without merit but can often be easier said than done. As a response to the creative inclinations of students who are attracted to enroll in music industry programs, an integrated and comprehensive music products program holds the promise of realizing creative vision from design all the way through to marketing. In the case of responding to the forces of the employment marketplace into which students will enter, this is an area of the music business that continues a pattern of long-term, slow and steady growth while providing a wide breadth of entry points on the production as well as management sides. In sum, music products is an area whose importance is far greater than a single chapter in your music business 101 text book. Fostering growth includes recognizing easily overlooked human and physical resources and working to build strategic partnerships across disciplinary borders. Despite the somewhat unexplored nature of the terrain, it is incumbent on program administrators and directors to ensure that fear of the unknown is not the barrier to entry. Instead, they may increase chances of success by relying on the orientation and abilities of program personnel; seeking support from potential partners in the sciences, theater, or art and design and; creatively re-evaluating existing program facilities for potential repurposing.

\section{Endlinks (embedded in body of text) \\ 1. https://www.sec.gov/Archives/edgar/ data/1021113/000110465913024368/a12-28783_110k. $\underline{\mathrm{htm}}$ \\ 2. https://www.marketwatch.com/story/guitar-cen- ters-proposed-debt-exchange-would-constitute-a-de- fault-moodys-2018-03-14 \\ 3. https://www.sweetwater.com/about/press-releases/00383}


Appendix 1. Media relative to sample programs with music products integration.

1. University of Illinois Urbana-Champaign, Department of Physics

a. Link to course website

b. Link to course syllabus

2. Appalachian State University, Hayes School of Music

a. Curriculum overview

3. Massey University of New Zealand, College of Creative Arts

a. Promotional videos: commercial music technology, software development

b. Curriculum overview

Appendix 2. Custom instrument amplifier project information.

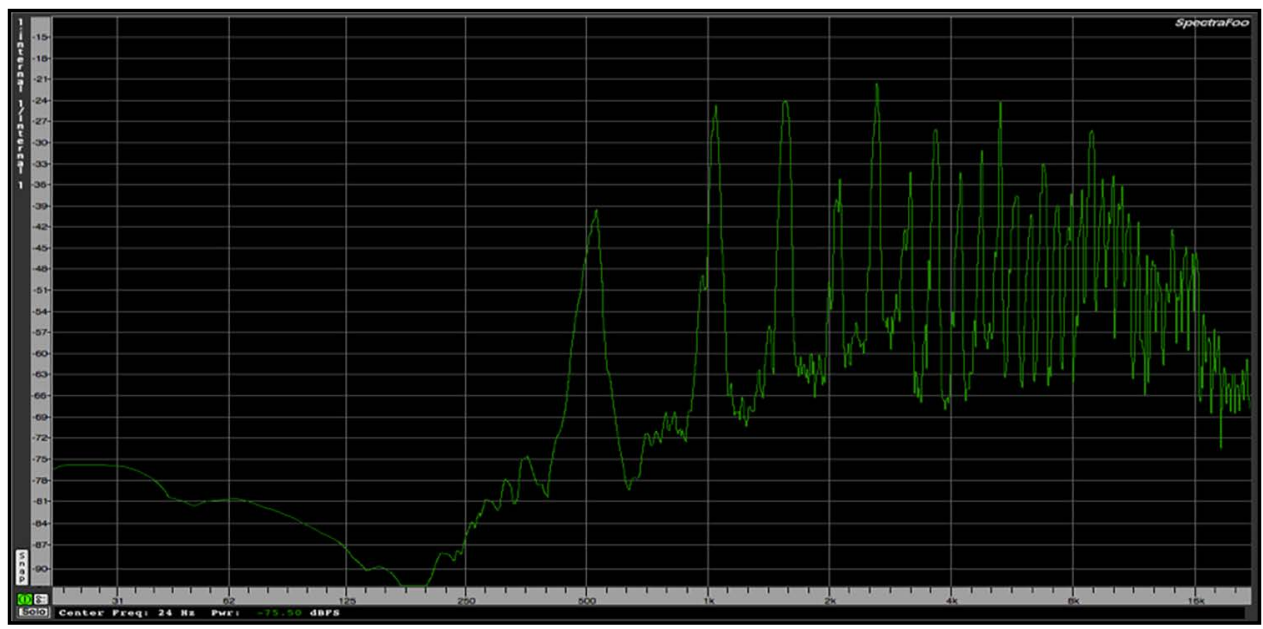

SpectraFoo frequency analysis of harmonica note (C5).

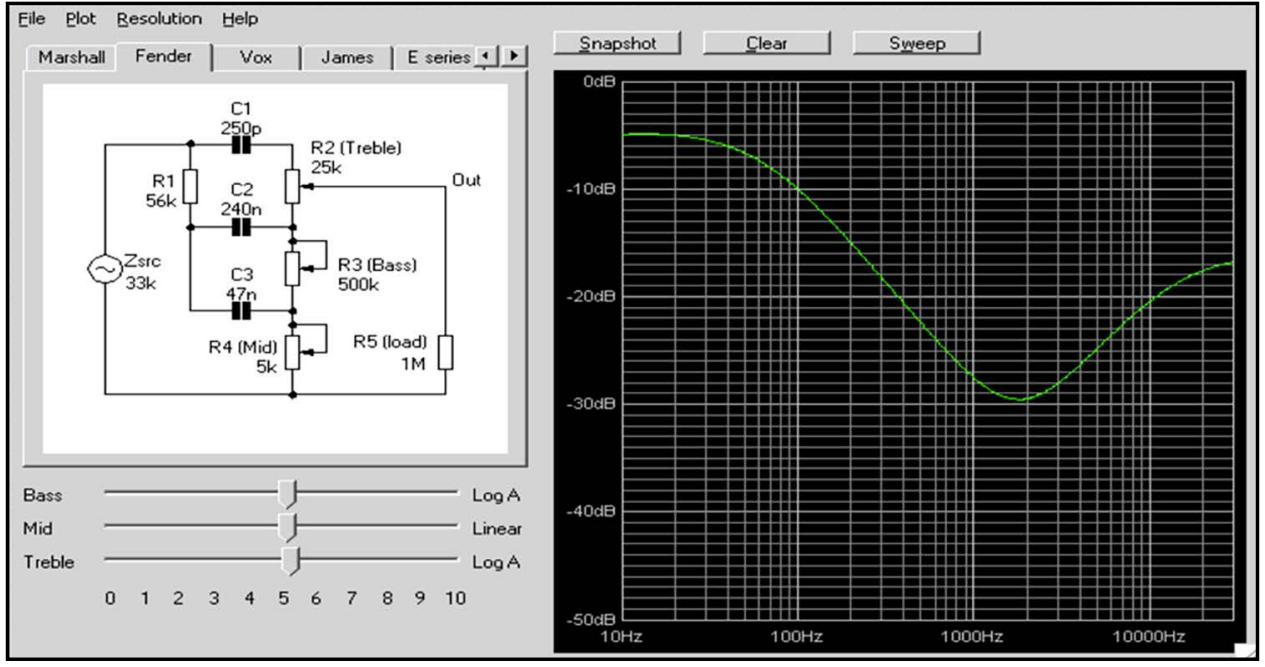

Tone Stack Calculator, interactive freeware to create custom tone circuit. 
Appendix 3. Equipment list and special resources for an applied audio lab.

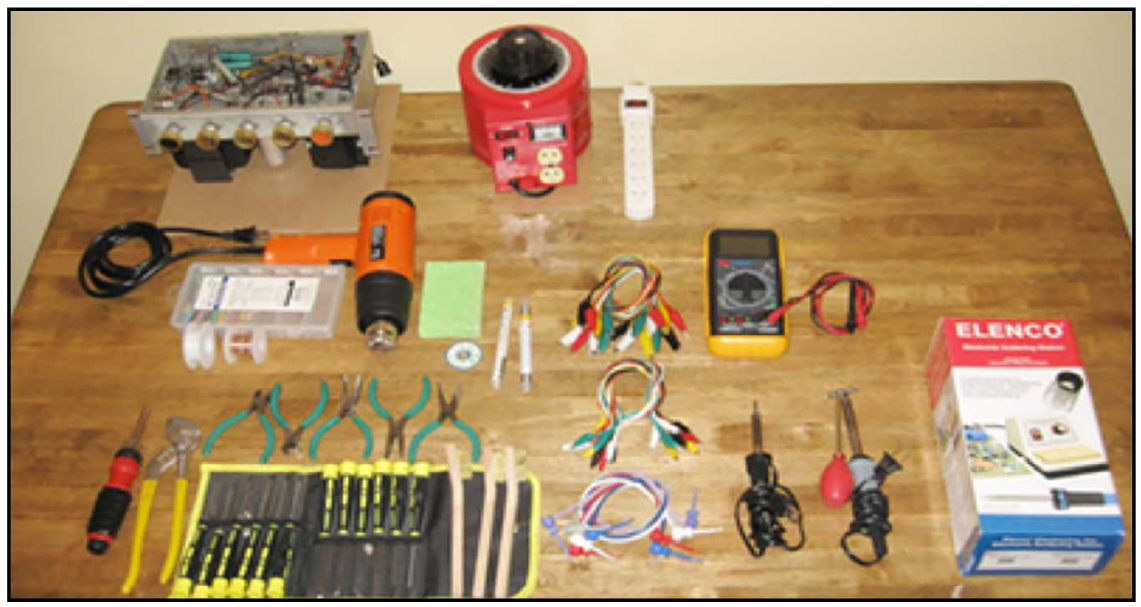

Example of program lab equipment $(\$ 1000)$.

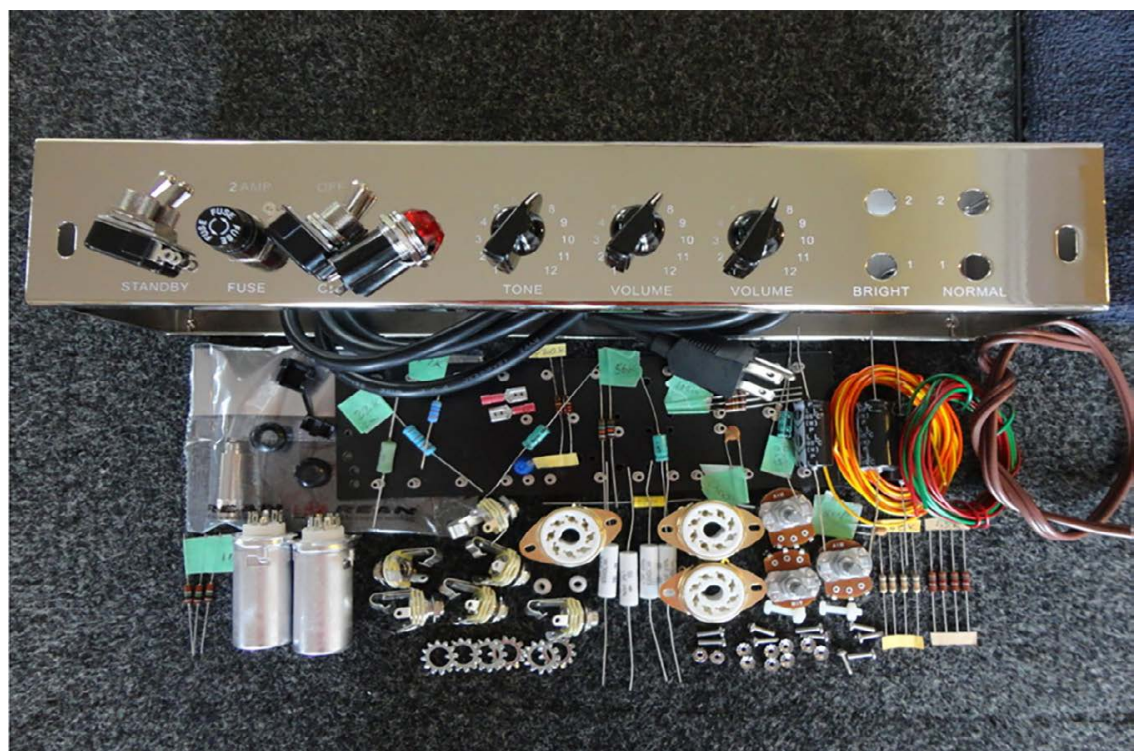

Example of mid-sized amplifier kit (student cost $\$ 200$ without speaker and cabinet).

Recommended Educational Resources

- Online

- YouTube channel: Uncle Spot

- AX84 reference library

- Valvewizard.co.uk

- Mutlimedia

- Weber, G. Tube Guitar Amplifier Servicing \& Overhaul [DVD]

- Books

- $\quad$ Blencowe, M. Designing Tube Preamps for Guitar and Bass

- Funk, D. How to Service Your Own Tube Amplifier

- $\quad$ Pittman, A. Tube Amp Book

- RCA Tube Manual 


\section{Websites}

- General amplifier discussion

- Fender discussion page:

http://www.fenderforum.com/forum.html

- Plexiboard: http://www.vintageamps.com/ plexiboard/index.php

- The gear page: http://www.thegearpage.net/ board/index.php?forums/amps-and-cabs.3/

- TDPRI, Amp Central: http://www.tdpri.com/ forums/amp-central-station.11/

- Builders' discussion pages (more technical)

- Doug Hoffman's site: http://el34world.com/Forum/index.php

- AX84 discussion forum: http://www.ax84.com/bbs/index.php

- DIY tube: http://www.diytube.com/phpBB2/ index.php?sid=1e7a7954d48b86bdf157d$\underline{520 \mathrm{c} 6 \mathrm{f} 7 \mathrm{~d} 8 \mathrm{~b} 1}$

\section{Where to Purchase Parts}

- Allen Amps: http://www.allenamps.com/

- Amplified Parts: https://www.amplifiedparts.com/

- Angela: http://www.angela.com/

- Antique Electronic Supply: https://www.tubesandmore.com/

- Hoffman: http://hoffmanamps.com/

- Kendrick: http://www.kendrick-amplifiers.com/

- Mojotone: http://www.mojotone.com/

- Watts Tube Audio: http://tubeamplifierparts.com/

- Weber: http://www.tedweber.com/amps/kits

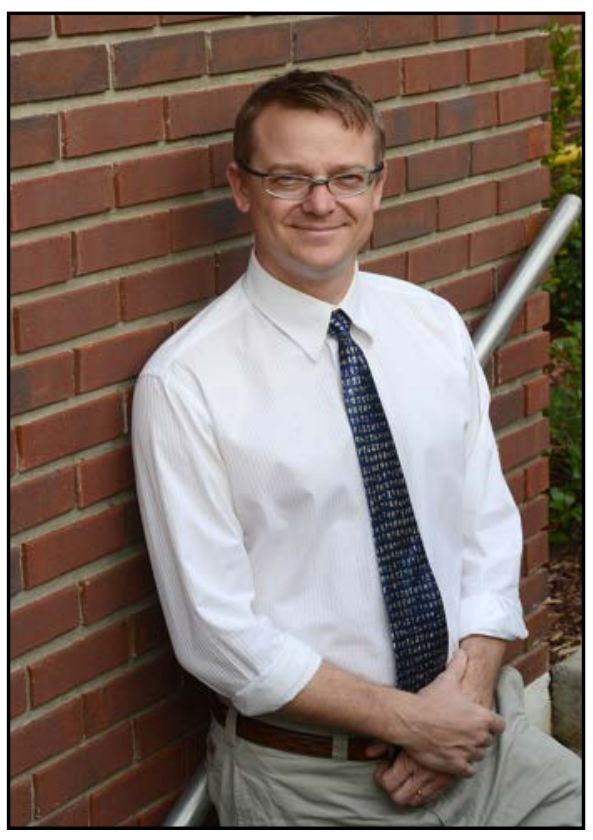

List of Tools for Beginners

\begin{tabular}{|l|l|}
\hline 30-watt soldering iron & Soldering station \\
\hline Digital mutlimeter & Socket set, "nut drivers" \\
\hline Needle nose pliers & Wire snips \& strippers \\
\hline Alligator clips & Screw driver set \\
\hline Allen wrenches set & Selection of "known good" components \\
\hline
\end{tabular}

Sample Project Parts List, Budget \& Time

\begin{tabular}{|l|l|l|}
\hline \multicolumn{3}{|c|}{$\begin{array}{c}\text { Sample parts list, 5F1 tweed champ, } 8 \text { watts } \\
\text { (estimated \$500 with cabinet and speaker) }\end{array}$} \\
\hline Circuit board & 3xtubes & Output transformer \\
\hline Power transformer & Power cord & Metal chassis \\
\hline 5 capacitors & 14 resistors & 2 grommets \\
\hline Power cord relief & Lamp assembly & Input jack \\
\hline Speaker jack & Potentiometer & 3x tube sockets \\
\hline Indicator bulb & Lamp jewel & Hardware 30pc. \\
\hline 20 ft. of wire & Speaker & Cabinet \\
\hline
\end{tabular}

Estimated Build Time, Difficulty

\begin{tabular}{|l|l|l|}
\hline & Experienced Builders & New Builders \\
\hline 1. Small amps & 4 hours & 8 hours \\
\hline 2. Mid-sized amps & 5 hours & 10 hours \\
\hline 3. Large amps & 6 hours & 12 hours \\
\hline
\end{tabular}

Paul Linden is Assistant Professor of Creative Media at Butler University. Dr. Linden carries twenty-five years of experience in various sectors of the recording industry. His professional resume includes credits as a performer, songwriter/publisher, agent, and manager for U.S.-based Blues groups in Western Europe. Dr. Linden holds a Ph.D. in Literature from Emory University (2003) and a Masters in Mass Communication from the University of Southern Mississippi (2013). His research interests include interdisciplinary and theoretical approaches to music industry studies. A selection of publications includes "Entrepreneurship: Theory and application in a university arts management setting," "Translating race and genre in popular music" and "Malcolm Chisholm: An Evaluation of Traditional Audio Engineering." Dr. Linden's research has been cited in the recent authoritative history of Fender amplifiers, The Soul of Tone: 60 Years of Fender Amps (Hal Leonard 2007) and Vintage Guitar Magazine. He is also a regular contributor to magazines like the Tone Quest Report and the French-based magazine, Blues \& Co. 


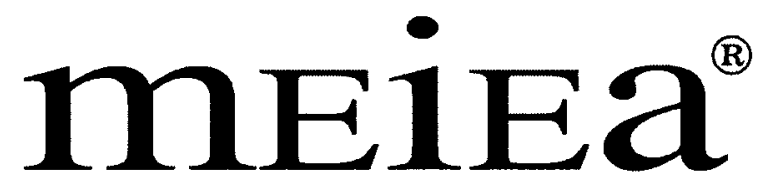

MUSIC \& ENTERTAINMENT INDUSTRY

EDUCATORS ASSOCIATION

\section{PROCEEDINGS OF THE \\ 2018 INTERNATIONAL SUMMIT}

OF THE

\section{MUSIC \& ENTERTAINMENT INDUSTRY EDUCATORS \\ ASSOCIATION}
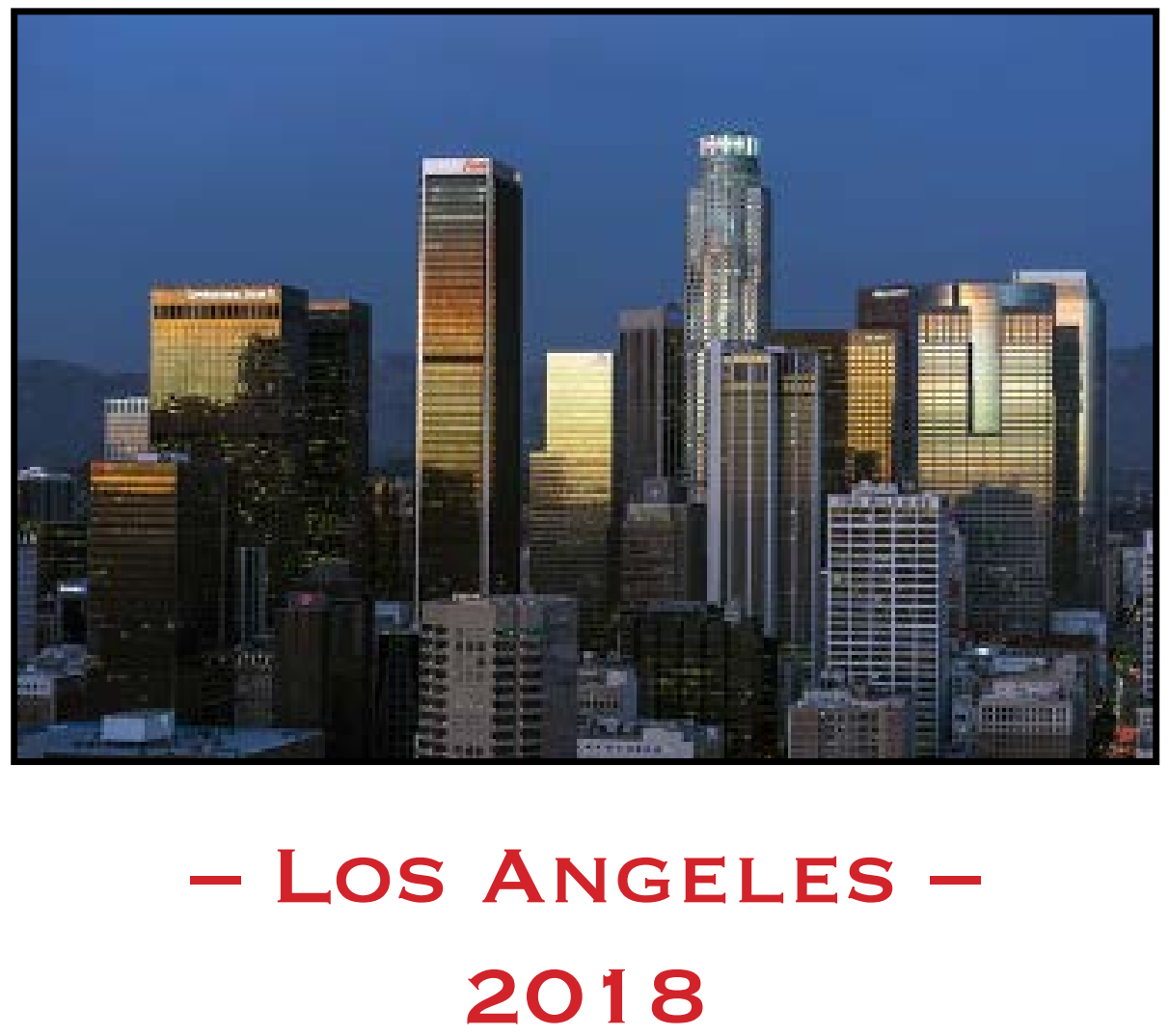

March 22 - 24, $2018 \cdot$ Embassy Suites by Hilton - Los Angeles/Glendale 